\title{
RETÓRICA E PERSUASÃO NA ARTE BARROCA: O TETO DA IGREJA DO SEMINÁRIO JESUÍTICO EM SANTARÉM
}

\author{
Magno Mello \\ Professor do Departamento de História da UFMG
}

A par de todo este percurso da pintura decorativa e do ambiente que circunda a figura do português António Simões Ribeiro, a decoração do teto plano da nave do Colégio Jesuíta em Santarém não pode permanecer isolado, como se fosse um caso marginal ou fruto de um momento arcaico. Pode vir a corresponder a um momento intermédio entre a absorção completa do sistema geométrico-matemático proveniente do gênero quadratura, no amadurecimento do modelo baquereliano, e ao mesmo tempo à conclusão da aprendizagem dos futuros pintores-decoradores da primeira metade do século XVIII, quiçá do próprio Simões Ribeiro.

Não se pode esquecer que já em 1723 este artista era ativo em Santarém numa encomenda tão significativa como a decoração quase completa da igreja dos Terceiros de São Francisco, isto é, uma irmandade de leigos com poder econômico expressivo e, provavelmente, a mais influente na cidade.

O Seminário Maior de Santarém deve figurar entre os mais suntuosos de todo o complexo artístico desta cidade ribatejana. Este Colégio foi fundado com o apoio régio, teve projeto já do Primeiro Barroco pelo arquiteto Mateus do Couto em 1647, refeito em 1653 e aprovado em Roma em 1673, servindo de modelo ao Colégio de Salvador da Bahia construído entre 1652 e 1672 (cujo autor se desconhece). A igreja da invocação de Nossa Senhora da Conceição pretendia romper com os esquemas tradicionais e introduzir a última palavra do moderno, mas num deliberado retorno "nacionalista" a formas pré-1580. As datas na fachada 1676 e 1711 - marcam o início e o fim da obra de pedraria.

Com um frontispício já barroco e tipicamente inserido nos formulários das igrejas jesuítas, fiel aos modelos quinhentistas vindos de Itália, como por exemplo a igreja do Gesù, em Roma (não esquecendo a de São Roque, em Lisboa), este edifício apresenta uma fachada do tipo compartimentado. Embora a pintura seja o ponto principal deste estudo, não se pode deixar de acentuar a relação entre a fachada do ex-Colégio Jesuíta em Santarém e a igreja do Colégio dos Jesuítas de Salvador, dentro das mesmas características maneiristas, com espaços compartimentados em divisões horizontais e verticais, associada a uma secção central enquadrada 
por volutas. Podemos ressaltar que, juntamente com a igreja jesuíta do Pará (no Brasil), o Seminário de Santarém e o Colégio em Salvador representam os monumentos jesuítas mais significativos em todo o mundo luso-atlântico daquela fase.

Do mesmo modo, as pinturas que se encontram no teto destes dois últimos edifícios compõem e coroam toda essa intenção de persuasão e triunfalismo que o Barroco português levou para a colônia brasileira. Numa tentativa de proximidade ainda maior, sabemos que nestas duas igrejas a fachada prepara terreno à ostentação da fase barroca, com a máxima expressão na pintura do teto da nave do Seminário em Santarém e na pintura do teto da antiga Livraria Jesuíta em Salvador, tendo esta sido idealizada pelo escalabitano António Simões Ribeiro. A decoração do interior do Seminário escalabitano veio a seguir, como o retábulo-mor de 1713 e os retábulos-mor em talha de Nossa Senhora da Glória e de Santo Estanislau Kostka, encomendados em Lisboa em 1702-1705, mas só colocados posteriormente.

O teto da nave do Seminário Maior de Santarém é um curioso modelo que aproveita a bidimensionalidade dos elementos estruturais e associa o quadro recolocado de grandes dimensões na única intenção decorativa possível, isto é, exibir de modo triunfal a iconografia cristã. Este forro colocava alguns problemas sob o ponto de vista técnico e temático e terá demorado um pouco mais a ser decidido: mas deve ter sido logo após a canonização de Santo Estanislau Kostka, em 1714, que já aí figura com destaque.

A exuberância deste teto está presente em toda a grande dimensão da nave, num suporte plano forrado em madeira. Desenvolve vasta decoração de falsa arquitetura, sem qualquer função volumétrica; no entanto, isola com uma falsa sanca um espaço ovalado, destinado ao tema principal, ocupado pela Imaculada Conceição, padroeira do colégio inaciano. A sua função está determinada pela imitação pictural da talha em todos os seus aspectos, ou seja, uma total simulação de volutas, grinaldas, arabescos variados, mísulas associadas com figuras de putti, sancas e molduras, como se fosse um gigantesco retábulo planimétrico colocado na horizontal a enquadrar cenas historiadas.

Um mundo próprio onde o relevo de imitação arquitetônica é apenas um contorno para o ciclo iconográfico, que, neste caso, é muito mais significativo do que a própria pintura como um modelo formal e estético. Um universo muito específico onde se misturam cores acentuadas, 
como o azul, o vermelho e o amarelo, na dinâmica dos nove quadros recolocados.

Não se conhece nenhum exemplo em Portugal onde tantas cenas associadas e uma pseudo-quadratura fossem representadas num único teto. A idéia geral de relevo é bastante ingênua, no entanto, as suas partes funcionam com alguma coerência e resolve-se perfeitamente a tridimensionalidade de alguns elementos arquitetônicos; principalmente quando estão associados a putti, muitas vezes em escorço sensível. Mas é visível ainda alguma insegurança.

Infelizmente, a execução desta complexa pintura não está documentada (ou ainda não foram encontrados os documentos) e não se conhece a sua autoria e a data exata de execução, sendo, porém provável que no ano de 1728 todo o teto estivesse concluído'. Estilisticamente, poderíamos datá-lo de 1715-1720.

Mas avançar com uma autoria e uma data precisas para esta pintura é arriscado e penso não ser o ponto mais importante neste primeiro momento de estudo. O ponto fulcral é tentar perceber a construção das cenas neste complexo de quadros recolocados, que nitidamente trai o piso da tradição dos caixotões e conduz o fruidor a uma vivência narrativa indiscutível. Aqui, a função da imagem é o aspecto mais importante como manifestação do sensível, da verdade e da fé: é a demonstração visual da doutrina católica, segundo a interpretação jesuíta.

Esta função tem lugar em toda a cultura artística, torna-se prática educativa e didática, utilizada como propaganda pela Igreja. Não se pode deixar de referir esta pintura como um esquema típico de programa político-social da Igreja, como um verdadeiro texto onde as formas e a composição se tornam a expressão dogmática da Igreja contra-reformista. Neste teto, e também no da capela-mor, executado algumas décadas mais

\footnotetext{
1 Jorge Custódio, Vítor Serrão, "Igreja do Seminário de Santarém”, Património Monumental de Santarém, Inventário Estudos Descritivos, Santarém, Câmara Municipal, 1997, p. 84: (...) nave rasgada segundo a lógica do estilo "chão" recebeu pintura prospéctica (anterior a 1728), a óleo, na esteira do forro de madeira, representando no medalhão central a Imaculada Conceição entre a glória de anjos, entre arquiteturas "trompe l'oeil", mísulas, balaustradas e arranjos de flores, diversas alegorias (as quatro partes do mundo) e cenas do Antigo Testamento, além da representação iconográfica de quatro pilares da Ordem dos Jesuítas, entre eles Santo Estanislau Kostka e São Luís Gonzaga, canonizados em 1727/28." É importante referir que nos óculos que representam os jesuítas não se encontra a figura de São Luís Gonzaga: confira os quatro jesuítas representados neste teto no esquema no final deste artigo.
} 
tarde, o engano visual ou o trompe l'oeil como técnica não são o mais importante, mas sim o poder de persuasão que encerra.

Para avançar com uma proposta cronológica, aponta-se os anos intermediários entre a canonização do Santo Estanislau Kostka e a década de vinte. Foi provavelmente o primeiro exemplo da aplicação de formas arquitetônicas pintadas tão do agrado dos jesuítas fora de Lisboa, incentivado pela intelectualidade local, oficializada na "Academia dos Laureados" criada em 1720 e que se reunia no Colégio.

Se o período cronológico parece estar mais próximo de uma coerência, a autoria permanece complexa e ainda sem indício de comprovação, carecendo de uma investigação em fontes documentais que parecem difíceis de concluir. Mediante um estudo mais pormenorizado dos elementos figurativos presentes nos quadros recolocados (os corpos mais desenvolvidos das figuras femininas e outros pormenores pertinentes ao colorido), nos óculos e nos putti que se posicionam sobre mísulas e nos óculos em forma de grinaldas, é flagrante a semelhança com os putti na curiosa representação figurativa sob um efeito mais livre e flutuante, evitando referimento a formas arquitetônicas e que ocupam o espaço atmosférico da abóbada da sacristia da igreja do Loreto, obra executada entre 1703 e 1705 e atribuída por Cirilo Volkmar Machado a António Machado Sapeiro². São ambas obras de uma mesma mão.

Em nossa opinião, é possível dizer que todos os grupos figurativos deste teto escalabitano foram executados por um artista diferente daquele que realizou as formas arquitetônicas, desde as mísulas, os capitéis, as volutas e alguns elementos do formulário do brutesco. É ainda possível pensar em António Lobo (? - 1719) para a autoria das personagens (devido à proximidade dos putti) ou a um mesmo ciclo de influência, pois a igreja do Loreto em Lisboa já contava com intervenções de Vincenzo Bacherelli (1682-1745), que trabalhava no teto da capela-mor deste edifício, podendo ter colaborado ou influenciado algum artista com menos capacidade técnica

2 Cirilo V. M., Collecção de Memórias (...), Lisboa, 1922, p. 70, diz ter trabalhado intensamente em tetos e em painéis em Lisboa, Santos-o-Novo e Camarate, falecendo em 1740. É citado por Vítor Serrão, "Marcos de Magalhães arquiteto e entalhador do ciclo da Restauração (1647-1664)", in Boletim Cultural da Assembleia Distrital de Lisboa, III série - n. ${ }^{\circ} 89$ - Tomo I, 1983, p. 24, e ainda por Gustavo Matos Sequeira, O Carmo e a Trindade, Câmara Municipal de Lisboa, vol.. II, Lisboa, 1939, pp. 244-245. Curiosamente, as pinturas de Camarate (igreja matriz) e Santos distanciam-se muito das formas da sacristia do Loreto. Quem sabe se Cirilo se referia a um outro teto (anterior) estruturado em pinturas tradicionais de caixotões, paralelo à produção decorativa do teto da nave, obra do italiano Giovanni Domenico Ponte em 1681-1684. 
e poder inventivo ainda incipiente na execução do teto da sacristia e, mais tarde, influenciar o ciclo pictórico do extenso teto do Seminário escalabitano através de desenhos.

Neste caso, é oportuno recordar a figura do Pe. Velásques, que a historiografia tradicional apontava como possível autor deste teto. Ora, a sua contribuição limitou-se certamente ao complexo programa iconográfico, identificando-o como professor e teólogo e não como pintordecorador.

Mesmo reconhecendo nesta obra uma complexidade estética, não podemos deixar de verificar o seu caráter experimental numa composição hesitante e na rude perspectiva frontal; uma ossatura arquitetônica de sabor arcaico e sem volume, negando os elementos básicos da perspectiva, com sentido de dinamizar verticalmente o espaço interno, ou seja, dar volumetria às formas arquitetônicas e o sentido de arrombamento espacial.

Ora, com a experiência adquirida na pintura do teto da sacristia da igreja do Loreto, com elementos formais de uma liberdade espacial inédita naquela época, seria contraditório que um mesmo artista pretendesse, no teto do Seminário em Santarém, usar um conceito tipológico ultrapassado, após um contacto com formas mais modernas e eficazes quanto ao ilusionismo perspéctico.

Note-se que a disposição dos putti, dispersos nesta membrana arquitetônica, exibe um belo escorço para uma visualidade a partir de baixo. As cartelas que narram os acontecimentos, isto é, as cenas do Antigo Testamento e as figurações das Quatro Partes do Mundo, estão dispostas em pronunciada obliqüidade.

Estas últimas, situadas nas extremidades do suporte, quase como óculos elevados por gigantescas mísulas que nascem do arranque da sanca real do teto, estão posicionadas para o espectador que penetra na grande aula em forma de nave única, num grande poder de persuasão. Entretanto, totalmente frontais são as cartelas de santos e putti, entre o quadro recolocado, as cenas do Antigo Testamento e os óculos dos respectivos santos inacianos.

Toda esta membrana arquitetônica adapta-se muito bem a esse conjunto figurativo, onde cada tema, cada figura isolada ou inserida em legenda, tem a sua função específica, a de apresentar ao fiel a vitória do mundo cristão nos quatro continentes, demarcado pela presença das idéias de Inácio de Loyola.

Citando Loyola, não se pode deixar de mencionar que o ponto importante da filosofia jesuíta advém do chamado «Princípio 
Fundamental», onde a regra do «Tanto Quanto» vem referida, isto é, (...) as coisas foram criadas para o homem e para ajudá-lo no prosseguimento do fim para o qual fora criado; de modo que, usará delas tanto quanto para alcançar o seu fim e tanto quanto se libertará delas se isso impedir a concretização do mesmo.

Tais "Princípio e Fundamento" repetem-se durante toda a experiência e orientam até o seu último e definitivo sentido, ou seja, a adoração de Deus através da relação ordenada do homem e das coisas. Todo o interior deste edifício e, principalmente, o teto da nave (ocupando todo o espaço do templo), vive para a "espetacularidade do culto" característica da liturgia barroca, tornando-se sempre mais próxima do teatro devido à profusão dos ornamentos, das policromias e dos dourados, tudo como num verdadeiro palco cenográfico.

Podemos dizer que a arquitetura barroca, e todo o seu aparato decorativo, unifica e dinamiza a igreja e o teatro num mesmo conceito. De uma ou de outra forma, faz a unificação da morte e da imortalidade, complementando-se numa única representação. Neste teto, devido à sua grande força figurativa, apesar do seu efeito de não-verticalidade espacial e da negação da perspectiva arquitetônica de forma erudita, assume uma capacidade de conceptualização visual extraordinária. Tem-se a impressão de que tudo está já encaminhado para a força e a persuasão dos Exercícios Espirituais de Inácio de Loyola.

Teria este teto a função mais direta de ensinar por meio de imagens pictóricas, procurando nas histórias a composição de lugar, tão necessária à meditação? Criar um espaço imaginário onde o fiel ou o fruidor se tornava um espectador diretamente envolvido na cena e, posteriormente, exercitando e adaptando-se na meditação da imagem como ator?

Além da sua função decorativa e específica na disposição perspéctica do espaço, as pinturas no teto funcionam também como método para facilitar as operações da memória por meios artificiais. Não nos esqueçamos que falamos de uma mensagem concebida no interior de um seminário jesuíta, com significativo conteúdo espiritual dirigido aos estudantes e seminaristas.

Apesar da ingenuidade dos elementos arquitetônicos, a mensagem espiritual está alinhada na mais atual prática jesuíta. É a tentativa de alcançar a epifania das imagens, dos pensamentos e dos locais. Aqui, procurou praticar-se uma ordem geométrica do mundo, transformando através do desenho o invisível em visível. Se esta pintura não apresenta ainda uma perspectiva sistematizada ou perfeitamente geométrica, como a pintura da 
capela-mor exibiria algumas décadas mais tarde, esse complexo pictórico deve ser considerado uma expressão pedagógica, cuja ação mais evidente é vista no quadro recolocado com o impacto da Imaculada Conceição representada em glória. Não se pode deixar de referir que a introdução da perspectiva na pintura dos tetos vem acompanhada da adaptação a uma nova iconografia, insistindo em novas regras e em novos modelos para a arte sacra.

Note-se que as mísulas, as volutas e toda a ossatura arquitetônica não correspondem a uma visão escorçada dos elementos arquitetônicos ali estabelecidos. Nem tão-pouco poderíamos encontrar uma relação com a tratadística contemporânea, como é o caso da pintura da abóbada da capela-mor do mesmo edifício, obra do Appeles Luís Gonçalves de Sena (1713-1790). Neste teto, a quadratura pode ser considerada apenas como um símbolo matérico de espacialidade. Sente-se muito mais a força de uma mensagem espiritual presa aos Exercícios Espirituais de Inácio de Loyola, diretamente na configuração de um espaço celestial, do que um espaço perspéctico construído matematicamente. A técnica da quadratura nesta representação foge a um condicionamento dependente do esquadro ou do compasso, necessários para uma configuração rigorosa do espaço que rompe o sentido de fechamento da cobertura.

Noutra conjuntura, o anônimo autor deste teto usa a "grade arquitetônica" que faz moldura ao quadro recolocado, numa função mais decorativa do que funcional, não criando elevação espacial, mas não deixando de construir uma idéia de espaço. Num primeiro momento, sentese um espaço aplanado, distante de formas que elevam o edifício a uma nova visualidade não reconhecida nas dimensões reais do templo.

Em toda a composição deste forro plano de madeira, nota-se a preocupação do autor em continuar o mesmo sistema de preenchimento dos espaços, como se fossem elementos de um grande retábulo ou a ilusão de um gigantesco suporte de madeira em relevo dourado, com figuras que povoam os óculos e as aberturas recortadas, entre estes e o quadro recolocado. Em todo este teto plano estão distribuidas oito cenas narrativas, o quadro central, os medalhões com os santos e as pequenas aberturas com as figuras de putti. Um misto de complexidade e movimento caracteriza este trabalho.

Como foi anteriormente assinalado, a produção quadraturística deste teto não está condicionada por soluções tratadísticas ou qualquer outro esquema geométrico preestabelecido. No entanto, podemos constatar que todas as quatro cenas que ladeiam o quadro recolocado foram pensadas 
para um espectador que se encontra numa posição oblíqua em relação à pintura. O mesmo serve para todos os putti, as quatro alegorias e os quatro continentes. A nossa hipótese de este teto ter sido pintado por duas mãos ou ter duas cronologias, com a estrutura arquitetônica datada anteriormente à aplicação "figurista", tem a sua veracidade e pode encontrar sentido para esta representação; no entanto, se pretendermos que António Machado Sapeiro era capaz de representar formas arquitetônicas na sacristia da igreja do Loreto em Lisboa, poderia igualmente representá-las aqui e associar um sistema de figurismo alegórico contemporâneo executado por um colaborador mais jovem.

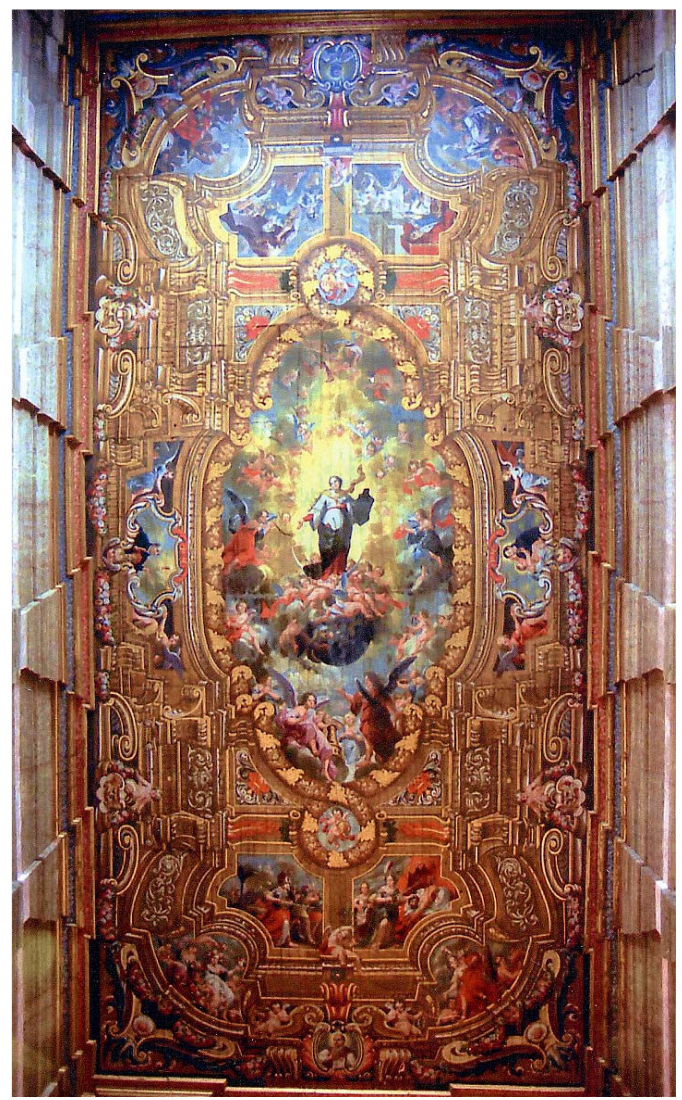

Teto do Seminário de Santarém. (anônima e sem data comprovada) 
Numa rápida avaliação deste sistema decorativo, torna-se obrigatório acrescentar dois aspectos a esta análise. Trata-se, primeiro, de situar os quatro cantos do suporte e, consequentemente, os apoios necessários para a sustentação desta arquitetura pintada. No remate da sanca e nos quatro enquadramentos angulares, a quadratura vem sustentada por dois pares de gordas volutas, marcando o início do entablamento que, por si só, aciona todo este plano superior em forma de "terraço pictórico." Este, por sua vez, não promove nenhum crescimento ascensional do interior do edifício, mas estabelece um sistema de relevo compartimentado povoado por mísulas, acantos, arabescos e volutas de vários formatos, sem qualquer compromisso com os pontos de fuga no prolongamento dos elementos arquitetônicos (falsamente) construídos.

$\mathrm{O}$ artista apenas imaginou fazer existir um plano superior, cuja estrutura emerge do arrombamento do suporte, que por um instante parece ser abobadado, sendo na realidade plano. Ora, nesta complexa e inédita estrutura pictórica não sentimos a força das arquiteturas pintadas que, com o avançar do século XVIII, será amplamente usada. Sente-se aqui um resquício dos momentos finais do século XVII, numa gramática arcaica e ainda não totalmente triunfalista e apologética como forma de estrutura, como no século seguinte, quando Luís Gonçalves de Sena intervém na decoração da capela-mor do mesmo edifício, em 1754.

Nota-se que a decoração da nave não condiciona o olhar a uma única visão. Se isso acontecer, é evidente a deformação total das mísulas ou do pseudo entablamento; todavia, numa observação fragmentada ou seccionada por pequenas zonas, encontramos algum relevo e sentimos que parte da quadratura cria sentido de projeção isolada. Admitindo que esta pintura não representa um momento de renovação cultural e artística, pois era o tempo de formas mais dinâmicas, já pertencente a um barroco erudito, percebe-se uma certa coerência de fusão entre arquitetura e pintura, construindo uma espécie de "membrana arquitetônica".

Enfim, é uma pintura que apresenta muitas questões e poucas respostas. Para além de uma erudita elevação arquitetônica, esta pintura marca a presença da quadratura em Portugal, anterior ao domínio das renovações formais que o Barroco promoverá dentro da pintura de tetos. Ainda no âmbito da discussão da sua possível cronologia, acreditamos que este teto possa ter sido executado entre 
1715 e 1720, antes do período em que António Simões Ribeiro iria fazer as suas intervenções na igreja da Ordem Terceira de São Francisco, numa proposta mais "culta" e mais moderna. No que respeita à cronologia, pensamos que o ano de 1715 seja o mais conveniente, pois, como foi anteriormente referido, a canonização do Santo Estanislau Kostka ocorreu em 1714 e neste teto ele figura de modo significativo. Quanto à autoria, é muito provável que este teto tenha sido executado por diversos artistas e que Bacherelli tenha fornecido uma espécie de idéia geral que seria seguida na fase da execução por artistas "baquerelianos."

Apenas reforçando o que já foi dito, grande parte do grupo figurativo do quadro recolocado em Santarém aproxima-se muito das figuras do teto da sacristia do Loreto. Será possível pensar que na própria igreja do Loreto tenha havido intervenções que foram repetidas em Santarém? Será possível pensar que tanto a sacristia do Loreto quanto a nave do Seminário escalabitano possam ter sido trabalhadas por um grupo de pintores sob a orientação de Bacherelli?

Outro aspecto que conduz a estas observações é que algumas destas figuras (tanto no Seminário como no Loreto) se assemelham a certas figurações típicas do receituário de Alessandro Gherardini (1655-1726), pintor figurista com grande fama em toda a Toscana e para o qual Vincenzo Bacherelli teria executado algumas representações da falsa arquitetura.

Não se pode deixar de referir que durante um período relativamente longo a pintura de tetos em Portugal, e naturalmente em Santarém, estava voltada para a aplicação de elementos essencialmente ornamentais, para o ornato, e menos estruturais ou funcionais. Era a fase das guirlandas, dos putti, dos balcões semicirculares, das balaustradas singelas e efêmeras e de entablamentos isolados. O período dos fustes e dos entablamentos relativos a uma ordem arquitetônica ou inserida numa formulação inspirada em tratados estava ainda para vir. Esta falsa arquitetura prolonga bem a real, mas acumula elementos soltos, sem ligação estrutural entre si. Toda a quadratura é essencialmente planimétrica, embora consiga ser opulenta, não escondendo, contudo a falta de domínio da nova linguagem. É ainda a estética da acumulação de 
volutas sobrepostas; nota-se deliberadamente a intenção de subalternizar a "membrana arquitetônica" em favor das imagens, alegorias e "enigmas" escondidos tão ao gosto dos Jesuítas, reunindo numa só composição cenas diversas, que nos tetos de caixotões seriam separadas. É essa unidade a grande novidade que esta pintura apresenta, muito mais do que uma preocupação em realizar formas perspecticamente corretas.

À margem de toda esta interpretação formal está a questão iconográfica disposta neste teto. De acordo com os estudos de Luís Moura Sobral para as suas análises da pintura barroca em Portugal, pode dizer-se que a pintura deste teto segue também a doutrina tipológica elaborada desde o século III pelos teólogos; trata-se da interpretação do Antigo Testamento como anúncio do que iria acontecer durante a vida de Cristo. ${ }^{3}$ Deste modo, os quatro cantos do mundo aparecem representados nos ângulos do teto da nave, distribuídos de modo que acima da entrada, à esquerda, está América e, à direita, Africa; do outro lado, em direção da capela-mor, está Europa à esquerda e, à direita, Ásia. Os quadros recolocados do templo estão organizados com cenas de profetisas do Antigo Testamento, que prefiguram a Imaculada Conceição representada no pano central.

À esquerda, e acima de quem entra, está Jahel, que tomou uma das estacas de sua tenda e um martelo; aproximando-se lentamente de Sisara, cravou-lhe um prego nas têmporas (Juízes 4-5); à direita de quem entra está Ester e Assuero (Ester 1-2). Acima da capela-mor e à esquerda está Débora, que organizou juntamente com Barac um exército contra as investidas de Jahel, rei de Canaã, e que após a vitória do povo israelita, compôs um cântico de celebração (Juízes 4-5). Ao lado de Débora, à direita, encontra-se Judite, que corta a cabeça de Holofernes que, com um estratagema, conquista a confiança do comandante assírio, pois tencionava atacar Israel (devese dizer que este episódio é muito similar àquele de David e Golias):

3 Conferência do Prof. Doutor Luís Moura Sobral na Faculdade de Letras de Lisboa, em 18/5/2000. Para a leitura iconográfica, agradeço as sugestões do Prof. Doutor Rafael Moreira, que propõe uma data c. 1715 e a atribuição ao jovem António Simões Ribeiro). 
passagens do Antigo Testamento que contam histórias de mulheres fortes e destemidas. No centro da cobertura, de modo majestoso e totalmente circundado por molduras de grinaldas, encontra-se o quadro recolocado com o tema da Imaculada Conceição na figura de Maria livre do pecado original, ou seja, imaculada e radiante de graça divina.

Enfim, um tema iconográfico tradicional usado de modo inovador, associando a idéia da compartimentação do espaço, mas sem as tradicionais separações dos caixotões ou dos tetos em forma de gamela, insistindo no sentido histórico e narrativo, ainda longe do efeito de espetacularidade que iria caracterizar os tetos futuros e cujo sentido global ainda nos escapa.

Numa tentativa de melhor especificar os elementos componentes na "armação arquitetônica" presente neste teto, pode dizer-se que é composto e organizado por grandes recortes de cartelas no eixo transversal com as imagens do jesuíta São Francisco de Borja, patrono da fundação das residências jesuítas, com a caveira coroada da imperatriz D. Maria de Portugal e a visão do cálice. A outra figura correspondente neste eixo é Santo Estanislau Kostka, com menino Jesus nos braços, padroeiro dos estudantes e seminaristas: ideal para um colégio. No eixo longitudinal, e em pequenos óculos associados a putti, estão representados Santo Inácio acima da entrada do edifício e São Francisco Xavier acima do arco triunfal. Sobre os frontões erguem-se uma irrealista composição arquitetural com pequenos capitéis jônicos e mísulas sustentando outras mais desenvolvidas e que preparam ou sustentam a abertura central. Logo a seguir à sanca real, estão presentes mísulas e gordas volutas bem desenvolvidas, que aparecem associadas a putti em significativo escorço. Estas formas aparecem frequentemente em tetos executados na última década do século XVII em Florença, principalmente pela figura de Alessandro Gherardini. O espaço aberto ocupado pela imagem da Imaculada ocupa a maior parte do teto, rodeada por grossa grinalda de frutos e folhas, que se enrola nas extremidades em dois círculos: sobre a entrada e o arco do cruzeiro querubins ostentam escudos com os monogramas MA (Maria), e do 
outro lado as iniciais IHS, associada aos três cravos da crucifixão de Cristo.

Todo o resto é preenchido por um fundo de nuvens numa exaltação da Senhora da Conceição, orago da igreja e padroeira do Reino. Pode ver-se ainda na base inferior do semicírculo um Arcanjo de manto vermelho e encostado numa espécie de escrivaninha e que explica com ar professoral algo a um grupo de cinco anjos atentos: decerto os Mistérios da Virgem. O maior apoia a Torre de David, uma das litanias de Maria, e os dois lateralmente dispostos erguem os braços em espanto. É o retrato místico de uma aula, com a qual os colegiais se identificariam. Ao centro, a Virgem, pisando a cobra que se enrosca no globo terrestre, com o crescente lunar sobre uma nuvem de anjinhos. A Imaculada irradia luz, entre dois anjos em vênias invertidas: um apresenta a palma; outro, a estrela. São símbolos marianos clássicos (Turris David, Stella Maris, Palma...) da ladainha.

Finalmente, o seu significado torna-se evidente na intenção de exaltar a Imaculada Conceição, o colégio jesuíta e a rainha de Portugal. O papel da Companhia parece escondido, mas está presente nas cartelas: são os Jesuítas ao serviço da Virgem em todo o mundo, levando de Lisboa a Santarém o novo modelo erudito. 